\title{
Estrogen and Aging Affect the Subcellular Distribution of Estrogen Receptor- $\alpha$ in the Hippocampus of Female Rats
}

\author{
Michelle M. Adams, ${ }^{1}$ Susan E. Fink, ${ }^{1}$ Ravi A. Shah, ${ }^{1}$ William G. M. Janssen, ${ }^{1}$ Shinji Hayashi, ${ }^{2}$ \\ Teresa A. Milner, ${ }^{3}$ Bruce S. McEwen, ${ }^{4}$ and John H. Morrison ${ }^{1}$ \\ ${ }_{1}^{1}$ Kastor Neurobiology of Aging Laboratories, Fishberg Research Center for Neurobiology, and Henry L. Schwartz \\ Department of Geriatrics and Adult Development, Mount Sinai School of Medicine, New York, New York 10029, \\ 2Laboratory of Endocrinology, Graduate School of Integrated Science, Yokohama City University, Yokohama 236-0027, \\ Japan, ${ }^{3}$ Department of Neurology, Weill Medical College of Cornell University, New York, New York 10021, and 4 Harold \\ and Margaret Milliken Hatch Laboratory of Neuroendocrinology, The Rockefeller University, New York, New York 10021
}

Estrogen replacement increases both the number of dendritic spines and the density of axospinous synapses in the hippocampal CA1 region in young rats, yet this is attenuated in aged rats. The estrogen receptor $\alpha(\mathrm{ER}-\alpha)$ is localized within select spines of CA1 pyramidal cells in young animals and thus may be involved locally in this process. The present study investigated the effects of estrogen on the ultrastructural distribution of ER- $\alpha$ in the CA1 of young (3-4 months) and aged (22-23 months) Sprague Dawley rats using postembedding immunogold electron microscopy. Within dendritic spines, most ER- $\alpha$ immunoreactivity (IR) was seen in plasmalemmal and cytoplasmic regions of spine heads, with a smaller proportion within $60 \mathrm{~nm}$ of the postsynaptic density. In presynaptic terminals, ER- $\alpha$-IR was clustered and often associated with synaptic vesicles. Significant effects of both aging and estrogen were observed. Quantitative analysis revealed that nonsynaptic pools of ER- $\alpha$-IR within the presynaptic and postsynaptic compartments were decreased (35 and $27 \%$, respectively) in the young estrogen-replaced animals compared with those that received vehicle. Such localized regulation of ER- $\alpha$ in response to circulating estrogen levels might directly affect synaptic signaling in CA1 pyramidal cells. No estrogen treatment-related differences were observed in the aged animals. However, 50\% fewer spines contained ER- $\alpha$ in the aged compared with young hippocampus. These data suggest that the decreased responsiveness of hippocampal synapses to estrogen in aged animals may result from age-related decrements in ER- $\alpha$ levels and its subcellular localization vis-à-vis the synapse. Such a role for spinous ER- $\alpha$ has important implications for age-related attenuation of estrogen-induced hippocampal plasticity.

Key words: CA1; ovariectomy; postembedding immunogold; electron microscopy; synaptic plasticity
The role of estrogen in controlling the reproductive axis at the level of the hypothalamus has been studied for many years and has been characterized in great detail (Fink, 1986). However, estrogens also affect synaptic communication in brain regions involved in cognitive processing, such as the hippocampus (Woolley, 1998), and these effects may be of particular importance in the context of aging, when both circulating estrogen levels change and hippocampal-dependent functions decline (Sherwin, 2000). Our current understanding of the effects of estrogen on synaptic plasticity in the hippocampus is based primarily on data from young animals. For example, dendritic spine density in CA1 pyramidal cells is sensitive to naturally occurring estrogen fluctuations in young animals (Woolley et al., 1990) as well as experimentally induced estrogen depletion and replacement (Gould et al., 1990; Woolley and McEwen, 1992, 1993; Woolley et al., 1996).

For the hypothalamus, it is well documented that aged animals do not have the same reaction to estrogen deprivation as young animals (Wise and Ratner, 1980; Steger et al., 1983; Gee et al.,

Received Nov. 8, 2001; revised Jan. 15, 2002; accepted Jan. 28, 2002.

This work was supported by National Institute on Aging Grant P01AG16765. We thank T. Oung, N. J. Riley, and A. P. Leonard for expert technical assistance and Dr. A. C. Gore for assistance with experimental design and helpful comments regarding this manuscript.

Correspondence should be addressed to John H. Morrison, Neurobiology of Aging Laboratories, Mount Sinai School of Medicine, Box 1639, New York, NY 10029-6574. E-mail: john.morrison@mssm.edu.

Copyright (ㄷ) 2002 Society for Neuroscience $0270-6474 / 02 / 223608-07 \$ 15.00 / 0$
1984; Mobbs et al., 1984; Rubin et al., 1985; Belisle et al., 1990; Hwang et al., 1990; Joshi et al., 1995). In addition, in the hippocampal formation, dendritic spines of dentate granule cells respond differently to estrogen replacement in middle-aged and young animals (Miranda et al., 1999). Recently, we reported that the increase in spine density after estrogen treatment in the CA1 of young animals is blunted in aged animals (Adams et al., 2001a). Together, these results suggest that the aged synapse may be fundamentally different from the young synapse in its capacity for plasticity, particularly in response to estrogen.

The expression of estrogen receptor- $\alpha(\mathrm{ER}-\alpha)$ and ER- $\beta$ in the brain, in particular in the hippocampal formation, provides a potential target and mechanism for effects of estrogen in brain regions and circuits mediating cognitive processes such as memory (Li et al., 1997; Shughrue et al., 1997, 1998; Weiland et al., 1997; Pau et al., 1998; Petersen et al., 1998; Register et al., 1998; Shughrue and Merchenthaler, 2000; Brinton, 2001). Recent evidence suggests that some of the effects of estrogen may not occur through regulating transcription but instead are mediated by membrane-bound ERs, resulting in activation of signal transduction cascades and second messenger systems (Toran-Allerand et al., 1999; Toran-Allerand, 2000; Brinton, 2001; Kelly and Levin, 2001). Interestingly, it was reported recently that ER- $\alpha$ is localized within select dendritic spines of CA1 pyramidal cells (Milner et al., 2001), suggesting that estrogen may be mediating its effects on synapses locally rather than through regulation of nuclear 

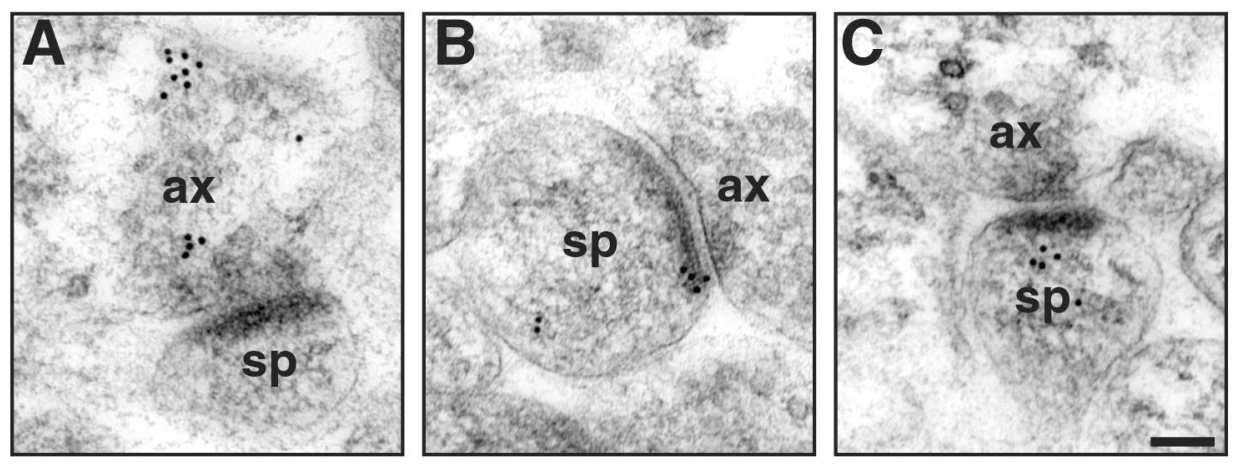

Figure 1. Distribution of ER- $\alpha$-IR within axospinous synapses in the stratum radiatum of the hippocampal CA1 region. Gold particles were observed to be localized both presynaptically $(A)$ and postsynaptically $(B, C)$. In the axon terminal $(A)$, gold particles were associated with small synaptic vesicles. In dendritic spines, gold particles were found within the head of the spine $(B, C)$ and affiliated within the postsynaptic density. Particles within the postsynaptic density were usually found in the more lateral portion. $a x$, Axon; sp, spine. Scale bar, $100 \mathrm{~nm}$.

transcription. Therefore, the present study was designed to examine the subcellular localization of ER- $\alpha$ and the effects of estrogen on the synaptic and perisynaptic distribution of ER- $\alpha$ in CA1 hippocampal pyramidal cells. The analyses revealed fundamental age-related differences in ER- $\alpha$ and estrogen-induced synaptic plasticity that have important implications for estrogen replacement in the context of age when estrogen levels and hippocampaldependent functions decline.

\section{MATERIALS AND METHODS}

Animals. A total of 21 female rats were used in the present study. Eleven young (3-4 months; $\sim 225 \mathrm{gm}$ ) and 10 aged (22-23 months; $\sim 350 \mathrm{gm}$ ) female Sprague Dawley rats were purchased from Harlan Sprague Dawley (Indianapolis, IN). Young rats were virgins, and aged rats were either virgins or retired breeders. Animals were housed in a temperaturecontrolled room (12 hr light/dark cycle; lights on at 7:00 AM). Food and water were available ad libitum. All experiments were conducted in accordance with the National Institutes of Health Guidelines for the Care and Use of Experimental Animals using protocols approved by the Institutional Animal Care and Use Committee at Mount Sinai School of Medicine.

Surgical procedures. Bilateral ovariectomy was performed under isoflurane anesthesia. After 7 d, a SILASTIC (Dow Corning, Midland, MI) capsule (capsule dimensions: inner diameter, $1.96 \mathrm{~mm}$; outer diameter, $3.18 \mathrm{~mm}$ ) filled with either $17-\beta$ estradiol (10\% in cholesterol) or cholesterol was implanted subcutaneously under anesthesia and remained for $2 \mathrm{~d}$. Young animals received an implant that was $1 \mathrm{~cm}$ long, and aged animals received an implant that was $2 \mathrm{~cm}$ long. Different implant lengths were used for animals of different ages to account for differences in body weights (Lauber et al., 1990; Funabashi et al., 1998), presumably resulting in comparable estrogen levels in young and aged rats. Moreover, our previous study used a similar estrogen replacement paradigm in a longerterm ovariectomy in aged animals and observed a similar uterine response, and the circulating estrogen levels were within a physiological range (Adams et al., 2001b). We determined that the vehicle and estrogen regimens after ovariectomy were effective by examining the uterus from each animal. In both young and aged rats treated with vehicle, uteri were very small and atrophied, and those that received estrogen displayed uterine hypertrophy. This estrogen-replacement and ovariectomy-interval regimen in the present study was chosen to relate our findings to previous studies that have used a similar time course (Weiland, 1992; Woolley and McEwen, 1992, 1993, 1994; Gazzaley et al., 1996; Woolley et al., 1996, 1997; Adams et al., 2001a). It should also be noted that the tissue blocks used in the present study were also examined in a previous study (Adams et al., 2001a) in which it was demonstrated that aged animals have a blunted spine response compared with young animals; however, the aged rats are still able to change the synaptic distribution of NMDA receptors after estrogen treatment. Thus, using the present technique, one can examine multiple aspects of receptor distribution in the same sets of animals and minimize interexperimental variability.

In addition to the estrogen-manipulated young and aged rats, one young rat was perfused on proestrus, and blocks from the CA1 region were processed and postembedding immunogold for ER- $\alpha$ was performed as described below. This pilot study was performed to equate the labeling pattern evident with postembedding immunogold with the reported observations based on pre-embedding diaminobenzidine-based localization (Milner et al., 2001). Our postembedding labeling had sim- ilar patterns to the pre-embedding labeling described by Milner et al. (2001) (see Results and Fig. 1).

Tissue processing and perfusion. Two days after the capsules were implanted, animals were anesthetized with $30 \%$ chloral hydrate and perfused transcardially with $2 \%$ dextran in $0.1 \mathrm{M}$ phosphate buffer (PB;

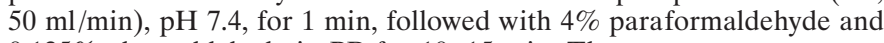
$0.125 \%$ glutaraldehyde in PB for 10-15 min. The carcasses were examined to confirm complete removal of both ovaries and the presence of the subcutaneous implant. The uterus of each animal also was examined to determine whether the estrogen replacement was effective, with uterine hypertrophy seen only for estrogen-treated animals. No animals in the present study had obvious pituitary tumors, incomplete removal of ovaries, or lack of implant. The brains were removed and post-fixed overnight. Two blocks from the dorsal hippocampus $(\sim 1 \mathrm{~mm}$ thick) were randomly selected from each animal and processed for postembedding immunogold.

Postembedding immunogold. Freeze substitution and low-temperature embedding of the specimens was performed as described previously (Van Lookeren Campagne et al., 1991; Hjelle et al., 1994; Chaudhry et al., 1995). Slices were cryoprotected by immersion in increasing concentrations of glycerol in PB $(10,20$, and $30 \%)$ and were plunged rapidly into liquid propane cooled by liquid nitrogen $\left(-190^{\circ} \mathrm{C}\right)$ in a Universal Cryofixation System KF80 (Reichert-Jung, Vienna, Austria). The samples were immersed in $1.5 \%$ uranyl acetate (for en bloc fixation) in anhydrous methanol $\left(-90^{\circ} \mathrm{C}, 24 \mathrm{hr}\right)$ in a cryosubstitution Automated Freeze Substitution unit (Leica, Vienna, Austria). The temperature increased in steps of $4^{\circ} \mathrm{C} / \mathrm{hr}$ from $-90^{\circ} \mathrm{C}$ to $-45^{\circ} \mathrm{C}$. The samples were washed with anhydrous methanol and infiltrated with Lowicryl HM20 resin (Electron Microscopy Sciences, Ft. Washington, PA) at $-45^{\circ} \mathrm{C}$ with a progressive increase in the ratio of resin to methanol for $1 \mathrm{hr}$ each, followed with pure Lowicryl (overnight). Polymerization was performed with ultraviolet light $(360 \mathrm{~nm})$ at $-45^{\circ} \mathrm{C}$ for $48 \mathrm{hr}$, followed by $24 \mathrm{hr}$ at room temperature.

The stratum radiatum of the CA1 region $(\sim 150-200 \mu \mathrm{m}$ from the cell bodies) was identified and sectioned. Pairs of ultrathin sections $(\sim 70-80$ $\mathrm{nm}$ thick as determined by interference colors) were cut by diamond knife on a Reichert-Jung ultramicrotome and mounted on nickel mesh grids for immunogold analysis. The mesh grids with ultrathin sections for the immunolabeling studies were treated with a saturated solution of $\mathrm{NaOH}$ in absolute ethanol, rinsed, and incubated in the following solutions at room temperature: $0.1 \%$ sodium borohydride and $50 \mathrm{~mm}$ glycine, and then Tris-buffered saline containing $2 \%$ human serum albumin. Single immunolabeling was performed, and sections were incubated with primary antibody (Okamura et al., 1992) (dilution of 1:2500) in the above diluent overnight, washed, and incubated in secondary gold tagged (10 $\mathrm{nm})$ antibody in Tris-buffered saline (2\% human serum albumin and polyethyleneglycol $20,000 \mathrm{Da} ; 5 \mathrm{mg} / \mathrm{ml}$ ). Sections were washed and dried, counterstained with $1 \%$ uranyl acetate and Reynolds lead citrate, and viewed on a Jeol (Tokyo, Japan) 1200EX electron microscope. Images were captured using the Advantage CCD camera (Advanced Microscopy Techniques Corporation, Danvers, MA). Control experiments omitting the primary antibody were performed, and no immunogold labeling was observed. The specificity of this primary antibody has been demonstrated previously in numerous experimental paradigms (Okamura et al., 1992; Alves et al., 1998; Milner et al., 2001).

Analysis of percentage of label of ER- $\alpha$. An analysis was performed of the percentage of synaptic profiles that contained ER- $\alpha$ immunoreactivity (IR). All synapses visible in an area of $\sim 3000 \mu \mathrm{m}^{2}$ were counted in the present analysis. Any profile that contained at least two gold particles 
per postsynaptic profile (i.e., in the synaptic cleft, postsynaptic density, or spine head) was considered positive for ER- $\alpha$. At least 100 synapses were counted for each animal.

Synaptic bin analysis of ER- $\alpha$. The immunogold particle density and distribution was analyzed using software developed in our laboratory (SynBin) (Adams et al., 2001a), based on principles regarding proximity to membranes articulated by Ottersen, Blackstad, and colleagues (Blackstad et al., 1990; Ruud and Blackstad, 1999). Accordingly, the position of each gold particle was determined as it relates to the postsynaptic and presynaptic membrane structures. The program analyzes the resulting data map and objectively assigns each gold particle to a given bin, with bin sizes and targeted synaptic domains established prospectively. The bin sizes are established on the basis of the lateral resolution of the electron microscopy techniques and to optimally separate synaptic and nonsynaptic pools of receptors. Through this process, a precise gold particle/bin density emerges that is an accurate reflection of gold particle distribution and density in different compartments of the synaptic complex.

Gold particle analysis was done on 35-50 randomly chosen spines per animal. Synapses cut obliquely that lacked clear visualization and delineation of classic synaptic structures such as presynaptic and postsynaptic membranes, a synaptic cleft, and postsynaptic density were excluded from the quantitative analysis. For the present analysis, $30 \mathrm{~nm}$ was chosen for the bin width because it assures high resolution yet comfortably accommodates the theoretical limit of resolution (i.e., $25 \mathrm{~nm}$ ). The following zones were defined for each synapse: (1) two postsynaptic bins, the first one $0-30 \mathrm{~nm}$ from the inner leaflet of the postsynaptic membrane and the second 30-60 nm from the postsynaptic membrane; (2) side bins that were $15 \mathrm{~nm}$ lateral to both of the postsynaptic bins; (3) the synaptic cleft; (4) a cytoplasmic bin that included gold particles $>60 \mathrm{~nm}$ from the postsynaptic membrane; (5) two presynaptic zones, one extending 0-30 $\mathrm{nm}$ from the inner border of the presynaptic membrane and the second extending 30-60 $\mathrm{nm}$ from the inner border of the presynaptic membrane; and (6) a presynaptic bin that included gold particles $>60 \mathrm{~nm}$ from the presynaptic membrane. With such a design, gold particles in the $0-30 \mathrm{~nm}$ postsynaptic density bin are unquestionably synaptic in location, whereas all other postsynaptic bins may include particles representing nonsynaptic pools of ER- $\alpha$. In addition, the lateral bins were used to establish a "buffer zone" at the lateral edge of the synapse to account for gold particles at the edge (i.e., within $15 \mathrm{~nm}$ ) that might be labeling proteins associated with the postsynaptic density.

Statistical analysis. Statistical analyses were performed using StatView 5.0 (Abacus Concepts, Inc., Berkeley, CA). Potential group differences in percentage of labeled synapses and number of gold particles per synaptic compartment between young ovariectomized vehicle- and estrogentreated animals, as well as aged ovariectomized vehicle- and estrogentreated rats, were evaluated by unpaired $t$ tests. ANOVA was performed to determine overall effects of age. Significance was set at $p<0.05$.

\section{RESULTS}

\section{Distribution of ER- $\alpha$ using postembedding immunogold electron microscopy}

A pre-embedding immunoelectron microscopic analysis demonstrated that ER- $\alpha$-IR is localized in both terminals and dendritic spines of young proestrus rats (Milner et al., 2001). In the present study, we observed a pattern of staining with postembedding immunogold that was qualitatively similar to that described with pre-embedding immunoelectron microscopy in all of the young and aged rats analyzed and included in the quantitative analysis (Fig. 1). Gold particles were localized within the postsynaptic density and the membrane of the perisynaptic region and were clustered within the cytoplasm of the head of the spine, perhaps representing a spinous pool of the receptor. In addition, gold particles were present in axon terminals, often affiliated with synaptic vesicles. In some cases, ER- $\alpha$ labeling was seen in the presynaptic and postsynaptic compartments of the same synaptic profile; however, most synaptic profiles had either presynaptic or postsynaptic labeling.

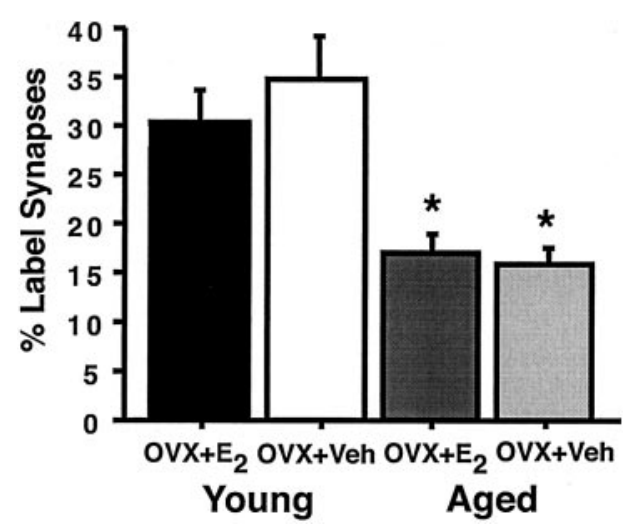

Figure 2. Percentage of ER- $\alpha$-IR-labeled synapses in young and aged rats. The graphs illustrate that the percentage of ER- $\alpha$-IR synapses decreases $(50 \%)$ with age $(* p<0.0001)$; however, there is no effect of estrogen treatment in either group (both $p$ values $>0.31$ ). $n=10$ for each age group. $O V X$, Ovariectomized; $E_{2}$, estrogen-treated; Veh, vehicle-treated.

\section{ER- $\alpha$ in young and aged estrogen- and vehicle-treated rats}

To determine whether the number of synapses that contained ER- $\alpha$-IR in the CA1 pyramidal cells of young and aged female rats changed with estrogen treatment, the percentage of synaptic profiles within a $3000 \mu \mathrm{m}^{2}$ area that were labeled for ER- $\alpha$ was analyzed. Only synapses that contained two or more gold particles within the postsynaptic profile were counted. In both estrogen- and vehicle-treated young animals, $\sim 30 \%$ of the synapses contained ER- $\alpha$-IR (30 and 34\%, respectively) (Fig. 2), with no significant difference in the number of labeled synapses between these two groups $(p>0.31)$ (Fig. 2). In addition, no difference was observed in the number of ER- $\alpha$-labeled synapses in the CA1 pyramidal cells between aged estrogen- or vehicletreated rats (17 and 16\%, respectively, $p>0.80$ ) (Fig. 2). Although there was no difference in the number of labeled synapses across estrogen treatment groups of the same age, we did observe a striking overall effect of age $(p<0.0001)$ (Fig. 2). Our results demonstrated an $\sim 50 \%$ reduction in the percentage of synapses that contained ER- $\alpha$-IR in the aged groups.

In addition to assessing whether the number of synapses that contain ER- $\alpha$ are altered in young and aged estrogen-treated rats, we determined whether the amount of ER- $\alpha$-IR per synapse was responsive to estrogen. To do this, we performed an analysis of the amount of ER- $\alpha$-IR as measured by the number of gold particles per synaptic profile. To quantify the synaptic distribution of ER- $\alpha$-IR, we used the computer-assisted method (i.e., SynBin) that was described in a previous study examining NR1 levels, the obligatory subunit for a functional NMDA receptor (Adams et al., 2001a). The present analysis revealed that labeled synapses in young animals had significantly less ER- $\alpha$ after estrogen replacement than those treated with vehicle, and these effects were confined to the presynaptic and postsynaptic compartments that were $>60 \mathrm{~nm}$ from their respective membranes (both $p$ values $<0.05$ ) (Fig. 3 and Table 1). In this material, it was not possible to determine decisively the degree to which the spinous pool of ER- $\alpha$ was associated with membranous specializations (e.g., caveolas or spine apparatus). However, in the presynaptic terminals, the ER- $\alpha$ was associated primarily with vesicles in which it could potentially affect neurotransmitter release. The difference between the estrogen- and vehicle-treated groups was 


\section{A. ER- $\alpha$ (> $60 \mathrm{~nm}$ pre-synaptically)}

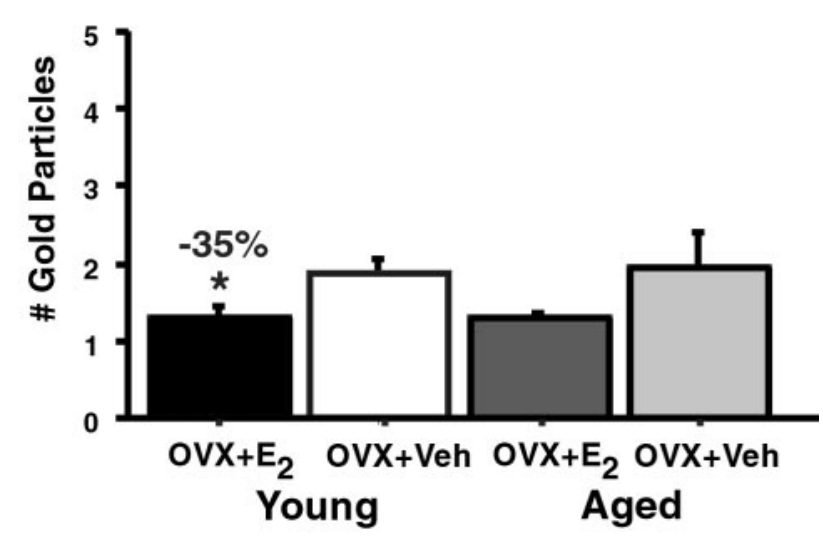

B. ER- $\alpha$ (> $60 \mathrm{~nm}$ post-synaptically)

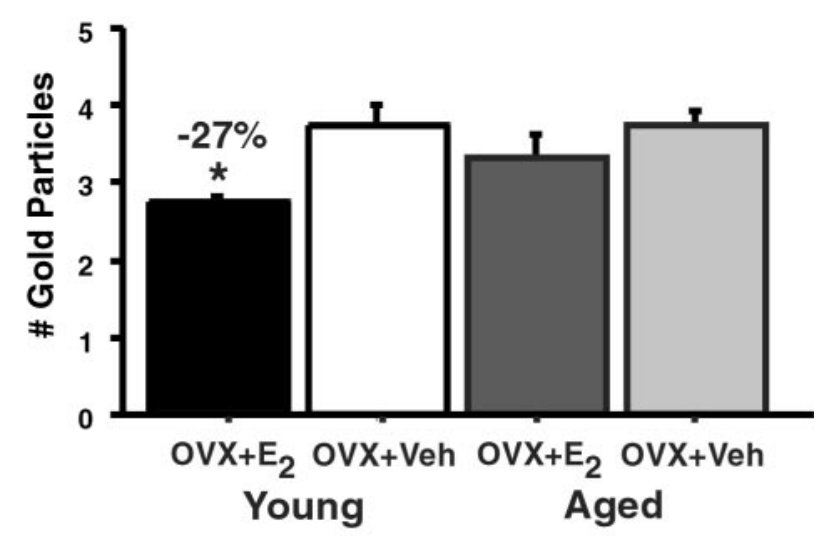

Figure 3. Levels of ER- $\alpha$-IR per synapse in young and aged vehicletreated $(V e h)$ and estrogen-treated $\left(E_{2}\right)$ rats. The amount of ER- $\alpha$-IR particles per synapse in young rats significantly decreases with estrogen treatment compared with vehicle both presynaptically $(A)$ and postsynaptically $(B)\left({ }^{*}\right.$ both $p$ values $\left.<0.05\right)$. No differences were observed in the estrogen- and vehicle-treated aged groups (both $p$ values $>0.16$ ). $n=5$ for each treatment group. $O V X$, Ovariectomized.

$\sim 35 \%$ presynaptically and $27 \%$ postsynaptically. However, we observed no difference in any compartment of the synapse between the aged ovariectomized rats given estrogen compared with those that received vehicle (all $p$ values $>0.16$ ) (Fig. 3 and Table 1 ). The trend suggested that the effect seen presynaptically in the young animals may also be occurring in the aged animals. However, because of the variability in the aged estrogen-treated groups, this effect was not significant.

\section{DISCUSSION}

Our results demonstrated that synaptic and spinous ER- $\alpha$-IR in CA1 pyramidal cells is sensitive to both aging and estrogen in female rats (Fig. 4). We found that the number of synapses that contain ER- $\alpha$-IR is decreased in aged animals compared with young rats. However, the percentage of ER- $\alpha$-IR-labeled synapses is not affected by estrogen in either young animals or aged animals. Although the number of synapses with ER- $\alpha$-IR is not different between young rats that received vehicle or estrogen, the amount of ER- $\alpha$-IR per labeled synapse is decreased in young estrogen-treated rats compared with those that received vehicle. However, no such regulation by estrogen was observed in aged animals. The present findings regarding ER- $\alpha$ may explain our previous observation that synapse number in aged CA1 is not increased by estrogen, although it is increased in CA1 of young female rats (Adams et al., 2001a).

\section{Synaptic and perisynaptic ER- $\alpha$ is regulated by circulating estrogen in CA1 of young females}

Many studies have demonstrated that in both young animals and cell lines exposed to estrogen, ER- $\alpha$ and its mRNA are reduced (Osterlund et al., 1998; Patisaul et al., 1999; Taleghany et al., 1999; Funabashi et al., 2000; Nephew et al., 2000; Schreihofer et al., 2000), and it is presumed in these cases that the reduction in ER- $\alpha$ is a critical element in regulating the transcriptional effects of estrogen. Interestingly, the present results show that ER- $\alpha$ protein is reduced in a very specific manner in the presynaptic pool associated with vesicles and the spinous pool, demonstrating a highly localized regulation in response to decreased estrogen that would presumably affect any local effects of estrogen on CA1 synapses. Such an effect is consistent with the notion of classic denervation supersensitivity, whereby the levels of a receptor are increased when the levels of the ligand of that protein are reduced (Miledi and Potter, 1971). An alternative explanation to the idea of classic denervation supersensitivity is that the ER- $\alpha$ is redistributed within the terminals and spines. Estrogen replacement in young animals has been shown to increase the density of spines and axospinous synapses in the CA1 region of the hippocampus (Gould et al., 1990; Woolley and McEwen, 1992, 1993; Woolley et al., 1996; Adams et al., 2001a). In addition, in the same young animals as used in the present study, estrogen treatment increased the density of axospinous synapses (Adams et al., 2001a). Therefore, it is also possible that as the number of spines increases with estrogen treatment, the amount of ER- $\alpha$ remains the same but is redistributed among the new spines and then effectively diluted over the short term. In addition, estrogen replacement has been shown to increase the number of multisynaptic contacts and alter the shape of synaptic boutons (Woolley et al., 1996; Yankova et al., 2001), and, in particular, it is the spine that grows out to make contact with the pre-existing axospinous synapse. In this connection, the use of radioimmunocytochemistry has demonstrated estrogen induction of IR for spinophilin, a spine-specific protein, in the apical and basal dendritic fields of CA1 where the new spine synapses are found (Brake et al., 2001). Therefore, the present result in young animals with estrogen treatment showing a decrease in ER- $\alpha$ may result from a redistribution of ER- $\alpha$-IR within the affected terminals and spines, as well as or in lieu of a direct effect on transport or local synthesis of ER- $\alpha$.

These pools of ER- $\alpha$ in the terminals and spines of CA1 have only recently been appreciated (Milner et al., 2001), and the function of such synaptic and perisynaptic ER- $\alpha$ remains to be elucidated, although multiple, rapid, nongenomic effects of estrogen have been described in both neural and non-neural tissue (Toran-Allerand et al., 1999; Brake et al., 2001; Brinton, 2001; Kelly and Levin, 2001). The presynaptic pool of ER- $\alpha$ is notably associated with vesicles and thus may be related to effects on neurotransmitter release (Becker, 1990) and reuptake (O'Malley et al., 1987) that have been described for estrogen. Postsynaptically, multiple molecular targets for mediation of rapid, local effects have been identified, particularly with respect to second messenger systems, such as cAMP response element-binding pro- 


\begin{tabular}{|c|c|c|c|c|c|c|}
\hline Bin designation & Young estrogen & Young vehicle & $p$ value & Aged estrogen & Aged vehicle & $p$ value \\
\hline \multicolumn{7}{|l|}{ Postsynaptic } \\
\hline $0-30 \mathrm{~nm}(\mathrm{bin} \mathrm{A})$ & 0.456 & 0.574 & $p=0.36$ & 0.446 & 0.427 & $p=0.90$ \\
\hline $30-60 \mathrm{~nm}($ bin $\mathrm{B})$ & 0.294 & 0.332 & $p=0.68$ & 0.400 & 0.365 & $p=0.81$ \\
\hline $15 \mathrm{~nm}$ lateral extension of $\mathrm{A}$ & 0.056 & 0.054 & $p=0.95$ & 0.036 & 0.035 & $p=0.88$ \\
\hline $15 \mathrm{~nm}$ lateral extension of $\mathrm{B}$ & 0.016 & 0.016 & $\mathrm{~N} / \mathrm{A}$ & 0.024 & 0.025 & $p=0.96$ \\
\hline$>60 \mathrm{~nm}$ & 2.736 & 3.752 & $p<0.01$ & 3.334 & 3.715 & $p=0.35$ \\
\hline \multicolumn{7}{|l|}{ Synaptic cleft } \\
\hline Cleft bin & 0.094 & 0.092 & $p=0.96$ & 0.068 & 0.050 & $p=0.64$ \\
\hline Lateral to cleft bin & 0.016 & 0.032 & $p=0.49$ & 0.008 & 0.010 & $p=0.85$ \\
\hline \multicolumn{7}{|l|}{ Presynaptic } \\
\hline $0-30 \mathrm{~nm}$ & 0.086 & 0.126 & $p=0.46$ & 0.100 & 0.083 & $p=0.58$ \\
\hline $30-60 \mathrm{~nm}$ & 0.132 & 0.110 & $p=0.70$ & 0.056 & 0.150 & $p=0.09$ \\
\hline$>60 \mathrm{~nm}$ & 1.176 & 1.708 & $p<0.05$ & 1.190 & 1.760 & $p=0.26$ \\
\hline
\end{tabular}

Numbers in bold represent bins that displayed statistically significant differences.

\section{A. Young}

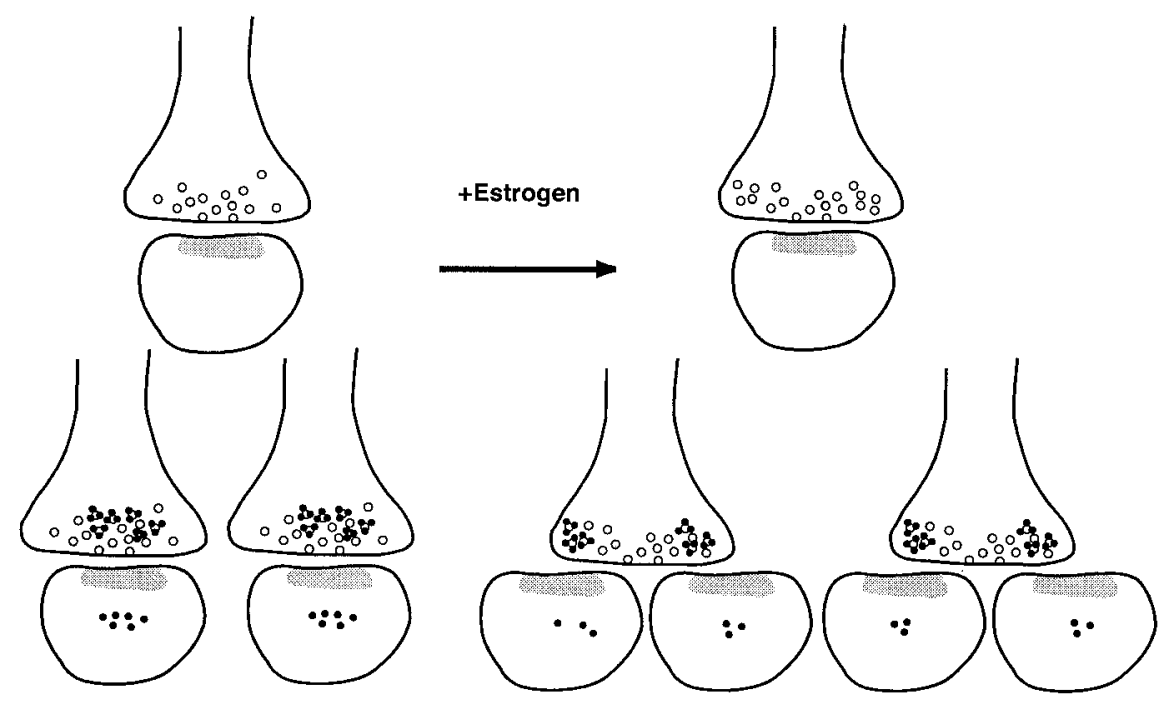

Figure 4. Schematic diagram illustrating the proposed mechanisms of estrogen-induced plasticity of ER- $\alpha$ in young $(A)$ and aged $(B)$ animals. Estrogen treatment either decreases the amount of ER- $\alpha$ per synapse in young animals or leads to a redistribution of the receptor resulting from the formation of new dendritic spines and alterations in presynaptic terminal shape. ER- $\alpha$ levels are unchanged in aged animals in both presynaptic and postsynaptic compartments, but there is an overall decrease in the percentage of terminals that express ER- $\alpha$-IR. Small black dots represent immunogold particles labeling ER- $\alpha$, open circles represent synaptic vesicles, and the gray zones represent the postsynaptic density.

\section{B. Aged}
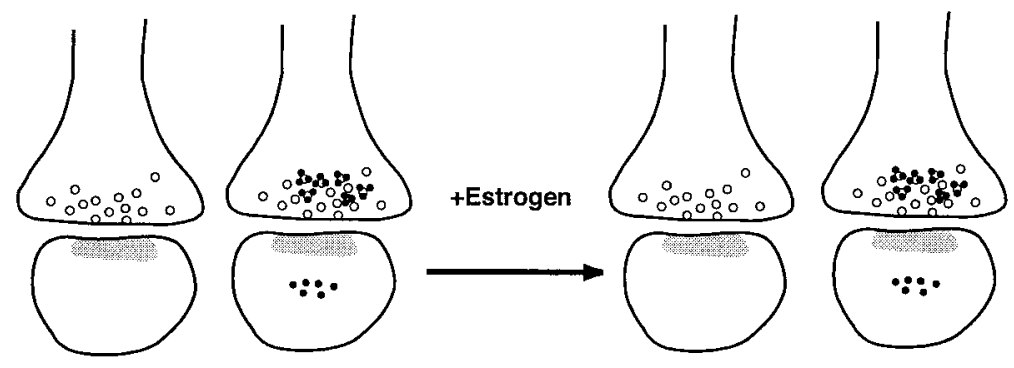

tein, phosphatidylinositol 3-kinase (PI3-kinase) and Akt, and G-protein-coupled receptors (Kelly et al., 1999; Razandi et al., 1999; Brinton, 2001) (K. T. Akama, S. E. Alves, W. G. Brake, S. J.Lee, B. S. McEwen, T. A. Milner, V. Znamensky, unpublished observations). One target of these actions appears to be the regulation of translation of mRNAs into proteins involving the
PI3-kinase/Akt pathway, which also strongly implicates ER- $\alpha$ (Simoncini et al., 2000; Brinton, 2001) (Akama, McEwen, Milner, Znamensky, unpublished observations). Some of this translational control by estrogens might involve the dendritic ER- $\alpha$ and the mRNA that are targeted to dendrites in hippocampal and other neurons (McEwen, 2001). Other effects might be mediated 
by ER- $\beta$ as well as ER- $\alpha$ and possibly by a putative novel receptor that is highly homologous to ER- $\alpha$, referred to as ER-X (ToranAllerand, 2000).

\section{Synaptic and spinous ER- $\alpha$ is decreased in CA1 of aged females}

Our previous study demonstrated that the increase in CA1 axospinous synapses in young animals is attenuated in aged females (Adams et al., 2001a). That analysis of axospinous synapse density was performed using the same animals as those used in the present study. Although the mechanism of action of estrogen regarding increased synapse number in CA1 is not resolved, there is significant support for the effect of estrogen being local in this case, rather than occurring through regulation of transcription in the nucleus (McEwen, 2001). If the spine response to estrogen in the hippocampus relies on ER- $\alpha$ levels in the axospinous synaptic junction and the levels of ER- $\alpha$ are decreased in the CA1 spines of aged females, then one would predict that the spine increase would be attenuated with age, which is precisely what occurs (Adams et al., 2001a). This phenomenon of an impaired response to ER- $\alpha$ is consistent with a study demonstrating that ER- $\alpha$ levels in the hypothalamus are decreased by estrogen in young but not aged rats (Funabashi et al., 2000). The decreased number of synapses that contain ER- $\alpha$-IR in aged animals as well as the decreased regulation of ER- $\alpha$-IR by estrogen in these same animals suggest that age-related shifts in ER- $\alpha$ may render the aged brain less plastic, which is consistent with other studies supporting a decrease in synaptic plasticity in the aging hippocampus (Cotman and Scheff, 1979; Scheff et al., 1980; Hoff et al., 1982a,b; West, 1984; Schauwecker et al., 1995; Stone et al., 2000).

In the present study, only one postovariectomy interval and estrogen-replacement regimen was examined. For the hypothalamus, it is well documented that aged animals do not have the same reaction to estrogen deprivation as young animals (Wise and Ratner, 1980; Steger et al., 1983; Gee et al., 1984; Mobbs et al., 1984; Rubin et al., 1985; Belisle et al., 1990; Hwang et al., 1990; Joshi et al., 1995). In addition, in the hippocampal formation, dendritic spines of dentate granule cells respond differently to estrogen replacement in middle-aged and young animals (Miranda et al., 1999). Thus, it is possible that a longer post-ovariectomy interval or estrogen replacement may change the response of ER- $\alpha$ in aged spines.

\section{The potential functional role of ER- $\alpha$ in spines}

This study not only confirms a previous study (Milner et al., 2001) demonstrating that ER- $\alpha$-IR is present within the presynaptic terminal and spines of CA1 pyramidal neurons but also indicates that it is responsive to estrogen in young animals and decreases with aging. Interestingly, most of the ER- $\alpha$-IR is within extrasynaptic membranes or the spine cytoplasm or is associated with presynaptic vesicles, rather than within the postsynaptic density. It will be of great importance to determine the localization and potential colocalized proteins of the spinous ER- $\alpha$-IR with greater precision. For example, it will be important to determine the degree to which the ER- $\alpha$-IR is sequestered in membranous caveola-like structures, as has been hypothesized (ToranAllerand, 2000), because such a localization would position ER- $\alpha$ to interact with the multiple signal transduction pathways that have been hypothesized to function within such an organelle in non-nervous system tissues (Schlegel et al., 1999). A critical role for ER- $\alpha$ in such caveolas was demonstrated recently in endothe- lial cells, in that caveolar ER- $\alpha$ was functionally and biochemically linked to nitric oxide synthase in a critical signaling module capable of regulating the local calcium levels. Such a link between ER- $\alpha$ and nitric oxide synthase could have profound local effects on synaptic plasticity in CA1. However, the substrate for such a complex is hypothetical at present, because caveolin and caveolincontaining structures do not appear to be present in the brain, although there may be a structural and functional homolog involving flotillin-anchored caveolas that may be a site for ER- $\alpha$ or a putative homologous ER (Kelly and Levin, 2001), which may be recognized by ER- $\alpha$ antibodies referred to by Toran-Allerand (2000) as ER-X. Although such a scenario is compelling, given the rich environment that it would offer regarding local effects of ER- $\alpha$ or its homolog, its characterization in the nervous system in general and in CA1 in particular will require extensive additional ultrastructural and biochemical analyses.

\section{REFERENCES}

Adams MM, Shah RA, Janssen WGM, Morrison JH (2001a) Different modes of hippocampal plasticity in response to estrogen in young and aged female rats. Proc Natl Acad Sci USA 98:8071-8076.

Adams MM, Oung T, Morrison JH, Gore AC (2001b) Length of postovariectomy interval and age, but not estrogen replacement, regulate $N$-methyl-D-aspartate receptor mRNA levels in the hippocampus of female rats. Exp Neurol 170:345-356.

Alves SE, Weiland NG, Hayashi S, McEwen BS (1998) Immunocytochemical localization of nuclear estrogen receptors and progestin receptors within the rat dorsal raphe nucleus. J Comp Neurol 391:322-334.

Becker JB (1990) Estrogen rapidly potentiates amphetamine-induced striatal dopamine release and rotational behavior during microdialysis. Neurosci Lett 118:169-171

Belisle S, Bellabarba D, Lehoux J-G (1990) Hypothalamic-pituitary axis during reproductive aging in mice. Mech Ageing Dev 52:207-217.

Blackstad TW, Karagülle T, Ottersen OP (1990) MORFOREL, a computer program for two-dimensional analysis of micrographs of biological specimens, with emphasis on immunogold preparations. Comput Biol Med 20:15-34.

Brake WG, Alves SE, Dunlop JC, Lee SJ, Bulloch K, Allen PB, Greengard P, McEwen BS (2001) Novel target sites for estrogen action in the dorsal hippocampus: an examination of synaptic proteins. Endocrinology 142:1284-1289.

Brinton RD (2001) Cellular and molecular mechanisms of estrogen regulation of memory function and neuroprotection against Alzheimer's disease: recent insights and remaining challenges. Learn Mem 8:121-133.

Chaudhry FA, Lehre KP, van Lookeren Campagne M, Ottersen OP, Danbolt NC, Storm-Mathisen J (1995) Glutamate transporters in glial plasma membranes: highly differentiated localizations revealed by quantitative ultrastructural immunocytochemistry. Neuron 15:711-720.

Cotman CW, Scheff SW (1979) Compensatory synapse growth in aged animals after neuronal death. Mech Ageing Dev 9:103-117.

Fink G (1986) The endocrine control of ovulation. Sci Prog 70:403-423.

Funabashi T, Kleopoulos SP, Kimura F, Mobbs CV (1998) Changes in neurotensin mRNA by estrogen in the female rat preoptic area during aging: an in situ hybridization histochemistry study. Gen Comp Endocrinol 112:364-371.

Funabashi T, Kleopoulos SP, Brooks PJ, Kimura F, Pfaff DW, Shinohara $\mathrm{K}$, Mobbs CV (2000) Changes in estrogenic regulation of estrogen receptor alpha mRNA and progesterone receptor mRNA in the female rat hypothalamus during aging: an in situ hybridization study. Neurosci Res 38:85-92.

Gazzaley AH, Weiland NG, McEwen BS, Morrison JH (1996) Differential regulation of NMDAR1 mRNA and protein by estradiol in the rat hippocampus. J Neurosci 16:6830-6838.

Gee DM, Flurkey K, Mobbs CV, Sinha YN, Finch CE (1984) The regulation of luteinizing hormone and prolactin in C57BL/6J mice: effects of estradiol implant size, duration of ovariectomy, and aging. Endocrinology 114:685-693.

Gould E, Woolley CS, Frankfurt M, McEwen BS (1990) Gonadal steroids regulate dendritic spine density in hippocampal pyramidal cells in adulthood. J Neurosci 4:1286-1291.

Hjelle OP, Chaudhry FA, Ottersen OP (1994) Antisera to glutathione: characterization and immunocytochemical application to the rat cerebellum. Eur J Neurosci 6:794-804.

Hoff SF, Sheff SW, Bernardo LS, Cotman CW (1982a) Lesion-induced synaptogenesis in the dentate gyrus of aged rats. I. Loss and reacquisition of normal synaptic density. J Comp Neurol 205:246-252. 
Hoff SF, Sheff SW, Cotman CW (1982b) Lesion-induced synaptogenesis in the dentate gyrus of aged rats. II. Demonstration of an impaired degeneration cleaning response. J Comp Neurol 205:253-259.

Hwang C, Pu H-F, Hwang C-Y, Liu J-Y, Yao H-C, Tung Y-F, Wang PS (1990) Age-related differences in the release of luteinizing hormone and gonadotropin-releasing hormone in ovariectomized rats. Neuroendocrinology 52:127-132.

Joshi D, Billiar RB, Miller MM (1995) Luteinizing hormone response to $N$-methyl-D,L-aspartic acid in the presence of physiological estradiol concentrations: influence of age and the ovary. Proc Soc Exp Biol Med 209:237-244.

Kelly MJ, Levin ER (2001) Rapid actions of plasma membrane estrogen receptors. Trends Endocrinol Metab 12:152-156.

Kelly MJ, Lagrange AH, Wagner EJ, Ronnekleiv OK (1999) Rapid effects of estrogen to modulate $\mathrm{G}$ protein-coupled receptors via activation of protein kinase $\mathrm{A}$ and protein kinase $\mathrm{C}$ pathways. Steroids 64:64-75.

Lauber AH, Romano GJ, Mobbs CV, Howells RD, Pfaff DW (1990) Estradiol induction of proenkephalin messenger RNA in hypothalamus: dose-response and relation to reproductive behavior in the female rat. Brain Res Mol Brain Res 8:47-54.

Li X, Schwartz PE, Rissman EF (1997) Distribution of estrogen receptor- $\beta$-like immunoreactivity in rat forebrain. Neuroendocrinology 66:63-67.

McEwen BS (2001) Estrogen's effects on the brain: multiple sites and molecular mechanisms. J Appl Physiol 91:2785-2801.

Miledi R, Potter LT (1971) Acetylcholine receptors in muscle fibres. Nature 233:599-603.

Milner TA, McEwen BS, Hayashi S, Li CJ, Reagan LP, Alves SE (2001) Ultrastructural evidence that hippocampal alpha estrogen receptors are located at extranuclear sites. J Comp Neurol 429:355-371.

Miranda P, Williams CL, Einstein G (1999) Granule cells in aging rats are sexually dimorphic in their response to estradiol. J Neurosci 19:3316-3325.

Mobbs CV, Gee DM, Finch CE (1984) Reproductive senescence in female C57BL/6J mice: ovarian impairments and neuroendocrine impairments that are partially reversible and delayable by ovariectomy. Endocrinology 115:1653-1662.

Nephew KP, Long X, Osborne E, Burke KA, Ahluwalia A, Bigsby RM (2000) Effect of estradiol on estrogen receptor expression in rat uterine cell types. Biol Reprod 62:168-177.

Okamura H, Yamamoto K, Hayashi S, Kuroiwa A, Muramatsu M (1992) A polyclonal antibody to the rat oestrogen receptor expressed in E. coli: characterization and application to immunohistochemistry. J Endocrinol 135:333-351.

O’Malley CA, Hautamaki RD, Kelley M, Meyer EM (1987) Effects of ovariectomy and estradiol benzoate on high affinity choline uptake, ACh synthesis, and release from rat cerebral cortical synaptosomes. Brain Res 403:389-392.

Osterlund M, Kuiper GG, Gustafsson JA, Hurd YL (1998) Differential distribution and regulation of estrogen receptor- $\alpha$ and $-\beta$ mRNA within the female rat brain. Brain Res Mol Brain Res 54:175-180.

Patisaul HB, Whitten PL, Young LJ (1999) Regulation of estrogen receptor beta mRNA in the brain: opposite effects of $17 \beta$-estradiol and the phytoestrogen, coumestrol. Brain Res Mol Brain Res 67:165-171.

Pau CY, Pau K-YF, Spies HG (1998) Putative estrogen receptor $\beta$ and $\alpha$ mRNA expression in male and female rhesus macaques. Mol Cell Endocrinol 146:59-68.

Petersen DN, Tkalcevic GT, Koza-Taylor PH, Turi TG, Brown TA (1998) Identification of estrogen receptor $\beta_{2}$, a functional variant of estrogen receptor $\beta$ expressed in normal rat tissues. Endocrinology 139:1082-1092.

Razandi M, Pedram A, Greene GL, Levin ER (1999) Cell membrane and nuclear estrogen receptors (ERs) originate from a single transcript: studies of ERalpha and ERbeta expressed in Chinese hamster ovary cells. Mol Endocrinol 13:307-319.

Register TC, Shively CA, Lewis CE (1998) Expression of estrogen receptor $\alpha$ and $\beta$ transcripts in female monkey hippocampus and hypothalamus. Brain Res 788:320-322.

Rubin BS, Elkind-Hirsch K, Bridges RS (1985) Hypothalamic LHRH in aging rats: effects of ovariectomy and steroid replacement. Neurobiol Aging 6:309-315.

Ruud HK, Blackstad TW (1999) PALIREL, a computer program for analyzing particle-to-membrane relations, with emphasis on electron micrographs of immunocytochemical preparations and gold labeled molecules. Comput Biomed Res 32:93-122.

Schauwecker PE, Cheng H-W, Serquinia RMP, Mori N, McNeill TH (1995) Lesion-induced sprouting of commissural/associational axons and induction of GAP-43 mRNA in hilar and CA3 pyramidal neurons in the hippocampus are diminished in aged rats. J Neurosci 15:24622470 .
Scheff SW, Bernardo LS, Cotman CW (1980) Decline in reactive fiber growth in the dentate gyrus of aged rats compared to young rats following entorhinal cortex removal. Brain Res 199:21-38.

Schlegel A, Wang C, Katzenellenbogen BS, Pestell RG, Lisanti MP (1999) Caveolin-1 potentiates estrogen receptor alpha (ERalpha) signaling: caveolin-1 drives ligand-independent nuclear translocation and activation of ERalpha. J Biol Chem 274:33551-33556.

Schreihofer DA, Stoler MH, Shupnik MA (2000) Differential expression and regulation of estrogen receptors (ERs) in rat pituitary and cell lines: estrogen decreases $\operatorname{ER} \alpha$ protein and estrogen responsiveness. Endocrinology 141:2174-2184.

Sherwin BB (2000) Oestrogen and cognitive function throughout the female lifespan. Novartis Found Symp 230:188-196.

Shughrue PJ, Merchenthaler I (2000) Evidence for novel estrogen binding sites in the rat hippocampus. Neuroscience 99:605-612.

Shughrue PJ, Lane MV, Merchenthaler I (1997) Comparative distribution of estrogen receptor- $\alpha$ and $-\beta$ mRNA in the rat central nervous system. J Comp Neurol 388:507-525.

Shughrue PJ, Scrimo PJ, Merchenthaler I (1998) Evidence for the colocalization of estrogen receptor- $\beta$ mRNA and estrogen receptor- $\alpha$ immunoreactivity in neurons of the rat forebrain. Endocrinology 139:5267-5270.

Simoncini T, Hafezi-Moghadam A, Brazil DP, Ley K, Chin WW, Liao JK (2000) Interaction of oestrogen receptor with the regulatory subunit of phosphatidylinositol-3-OH kinase. Nature 407:538-541.

Steger RW, Sonntag WE, Peluso JJ, Meites J (1983) Effects of ovariectomy and steroid replacement on hypothalamic LHRH content in aging female rats. Neurobiol Aging 4:53-57.

Stone DJ, Rozovsky I, Morgan TE, Anderson CP, Lopez LM, Shick J, Finch CE (2000) Effects of age on gene expression during estrogeninduced synaptic sprouting in the female rat. Exp Neurol 165:46-57.

Taleghany N, Sarajari S, DonCarlos LL, Gollapudi L, Oblinger MM (1999) Differential expression of estrogen receptor alpha and beta in dorsal root ganglion neurons. J Neurosci Res 57:603-615.

Toran-Allerand CD (2000) Novel sites and mechanisms of oestrogen action in the brain. In: Neural and cognitive effects of oestrogens, Novartis Foundation Symposium 230, pp 56-73. Chichester, UK: Wiley.

Toran-Allerand CD, Singh M, Sétáló Jr G (1999) Novel mechanisms of estrogen action in the brain: new players in an old story. Front Neuroendocrinol 20:97-121.

Van Lookeren Campagne M, Oestreicher AB, van der Krift TP, Gispen WH, Verkleij AJ (1991) Freeze-substitution and Lowicryl HM20 embedding of fixed rat brain: suitability for immunogold ultrastructural localization of neural antigens. J Histochem Cytochem 39:1267-1279.

Weiland NG (1992) Estradiol selectively regulates agonist binding sites on the $N$-methyl-D-aspartate receptor complex in the CA1 region of the hippocampus. Endocrinology 131:662-668.

Weiland NG, Orikasa C, Hayashi S, McEwen BS (1997) Distribution and hormone regulation of estrogen receptor immunoreactive cells in the hippocampus of male and female rats. J Comp Neurol 388:603-612.

West JR (1984) Age-dependent sprouting in the dentate gyrus demonstrated with anterograde HRP. Brain Res Bull 12:323-330.

Wise PM, Ratner A (1980) Effect of ovariectomy on plasma LH, FSH estradiol, and progesterone and medial basal hypothalamic LHRH concentrations in old and young rats. Neuroendocrinology 30:15-19.

Woolley CS (1998) Estrogen-mediated structural and functional synaptic plasticity in the female rat hippocampus. Horm Behav 34:140-148.

Woolley CS, McEwen BS (1992) Estradiol mediates fluctuations in hippocampal synapse density during the estrous cycle in the adult rat. J Neurosci 12:2549-2554.

Woolley CS, McEwen BS (1993) Roles of estradiol and progesterone in regulation of hippocampal dendritic spine density during the estrous cycle in the rat. J Comp Neurol 336:293-306.

Woolley CS, McEwen BS (1994) Estradiol regulates hippocampal dendritic spine density via an $N$-methyl-D-aspartate receptor-dependent mechanism. J Neurosci 14:7680-7687.

Woolley CS, Wenzel HJ, Schwartzkroin PA (1996) Estradiol increases the frequency of multiple synapse boutons in the hippocampal CA1 region of the adult female rat. J Comp Neurol 373:108-117.

Woolley CS, Weiland NG, McEwen BS, Schwartzkroin PA (1997) Estradiol increases the sensitivity of hippocampal cells to NMDA receptor-mediated synaptic input: correlation with dendritic spine density. J Neurosci 17:1848-1859.

Woolley CW, Gould E, Frankfurt M, McEwen BS (1990) Naturally occurring fluctuations in dendritic spine density on adult hippocampal pyramidal neurons. J Neurosci 10:4035-4039.

Yankova M, Hart SA, Woolley CS (2001) Estrogen increases synaptic connectivity between single presynaptic inputs and multiple postsynaptic CA1 pyramidal cells: a serial electron-microscopic study. Proc Natl Acad Sci USA 98:3525-3530. 